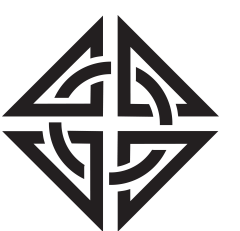

SCIENTIA
Sharif University of Technology

Scientia Iranica

Transactions A: Civil Engineering

http://scientiairanica.sharif.edu

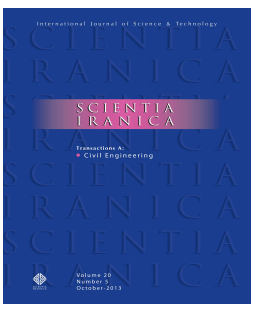

\title{
Sustainable use of stabilized flood mud as subgrade soil for low volume traffic roads
}

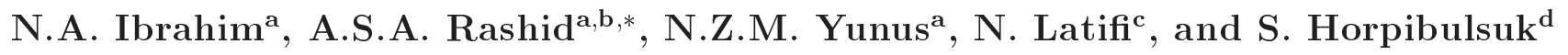 \\ a. Department of Geotechnics and Transportation, School of Civil Engineering, Faculty of Engineering, Universiti Teknologi \\ Malaysia, 81310, Skudai, Johor, Malaysia. \\ b. Centre of Tropical Geoengineering (GEOTROPIK), School of Civil Engineering, Faculty of Engineering, Universiti Teknologi \\ Malaysia, 81310, Skudai, Johor, Malaysia. \\ c. Department of Civil and Environmental Engineering, Mississippi State University, Box 9546, Mississippi State, USA. \\ d. Center of Excellence in Innovation for Sustainable Infrastructure Development, School of Civil Engineering, Suranaree University \\ of Technology, 111 University Avenue, Muang District, Nakhon Ratchasima 30000, Thailand.
}

Received 1 March 2018; received in revised form 21 September 2018; accepted 21 January 2019

\author{
KEYWORDS \\ Flood mud; \\ Subgrade; \\ Unconfined \\ compressive strength; \\ Microstructure; \\ SH85 stabiliser.
}

\begin{abstract}
This research aims to identify the basic properties of flood mud and the efficiency of biomass silica (SH85) as a stabilizer to improve the strength of this mud. Unconfined Compressive Strength (UCS) testing was carried out on untreated soil and soil treated with $2 \%, 4 \%$, and $9 \%$ SH85 contents within three and seven curing days. The microstructure of SH85 treated flood mud was investigated via Field-Emission Scanning Electron Microscopy (FESEM) and Energy-Dispersive X-ray (EDX) spectrometry. It was found that the strength of treated soil increased two to seven times that of the untreated soil where the highest strength was recorded at $949 \mathrm{kPa}$ following seven-day soil treatment by $9 \%$ SH85 content. A polynomial trend was observed with an $R^{2}$ value greater than $95 \%$ relationship between SH85 content and UCS in different curing periods. The seven-day UCS of SH85 treated flood mud met the strength requirement of $0.8 \mathrm{MPa}$ for Malaysian subgrade material of low traffic volume roads and the compressibility was significantly reduced when SH85 content was greater than 4\%. According to the FESEM and EDX results, cementitious products that promoted soil strength filled the voids of the treated soil.

(C) 2020 Sharif University of Technology. All rights reserved.
\end{abstract}

\section{Introduction}

On 24 December 2014, several provinces in Malaysia including Perlis, Perak, Kelantan, Terengganu, and Pahang were affected by heavy rainfall that triggered flooding [1]. Due to this flood event, layers of mud

\footnotetext{
*. Corresponding author. Tel.: +6075531591

E-mail addresses: nurulain5758@gmail.com (N.A. Ibrahim); ahmadsafuan@utm.my (A.S.A.Rashid); nzurairahetty@utm.my (N.Z.M.Yunus); nlatifi@cee.msstate.edu (N. Latifi); suksun@g.sut.ac.th (S. Horpibulsuk)
}

doi: $10.24200 /$ sci. 2019.50523 .1749 were formed throughout the region as the receding water left large amounts of material behind. The flood mud was disposed of without proper management, hence large amounts of waste. Due to environmental concerns, sustainable reutilization of mud deposit is considered for use as a construction material $[2,3]$. This mud soil can be used as a stabilized subgrade material for low traffic volume roads. The stabilized subgrade material for low volume roads must meet an Unconfined Compressive Strength (UCS) value of at least $0.8 \mathrm{MPa}$, as sanctioned by the Malaysia Public Work Department (PWD) specifications [4].

According to Datta et al. [5], roads carrying an average daily traffic of less than 400 vehicles per day 
are generally defined as low volume roads. It can also be described as having low cumulative number $(80 \mathrm{kN})$ of Equivalent Standard Axle Loads (ESALs) over the design life of the road [6,7]. Usually, low traffic volume roads are highly applicable to rural areas or light traffic load areas. Efficient road transportation services play an important role in developing countries and they improve the quality of life for the rural population. Low traffic volume roads serve as one of the key infrastructure systems that has become a matter of growing urgency in community development, intra-community trade of goods and services, and resource management activities. Therefore, it is important for this type of road to be well planned, located, designed, constructed, and maintained. The performance evaluation of these roads is an absolute necessity [5].

Chemical and polymer stabilizers such as sodium chloride, calcium chloride, cement, fly ash, and lime are among the best methods for improving the engineering properties of natural soil [8-29]. Given that the stabilization method is very cost effective and ensures rapid soil strength, it is widely used and has become popular in road construction [11]. Driven by relatively low cost, simplicity, low carbon dioxide emission, and shorter curing time, nowadays, non-traditional stabilizers are being developed constantly for better soil stabilization [19,30,31]. It has become clear by now that non-traditional additives can properly improve soil strength in a shorter curing time than conventional stabilizers (cement and lime) [20,32-34].

Latifi et al. [33] investigated the treated tropical laterite soil with calcium-based powder stabilizer (SH85). A series of compressive strength tests were performed to determine the strength performance of the treated soil. The strength test results showed that the SH85 stabilized laterite soil was roughly five times stronger than the untreated soil upon the seven days of curing period. They also found a significant increase in the compressibility property of treated samples within the curing time duration. The formation of white lumps in the treated soil fabric, with the cementitious gel filling the pores in the soil structure, was observed in the images of Field-Emission Scanning Electron Microscopy (FESEM), which proved that a new strength product was developed from the stabilization process. The same observation was made by Latifi et al. [31], who found that the strength of treated montmorillonitic and kaolinitic clays increased significantly in the early stages of curing. Although this non-traditional stabilizer significantly improved the strength of laterite and clay soils, the effects of these products on the chemical composition (stabilizing mechanisms) and performance prediction are not fully understood, especially when they are mixed with waste soil material such as flood mud soil.

Therefore, the main objective of the present work is to investigate the potential of reusing flood mud soil from the flooded area at Kuala Krai, Kelantan for constructing a subgrade layer for the low volume traffic roads in the region. In this research, the physical, mechanical, and micro-structural characteristics of the flood mud are studied. In addition, some basic geotechnical parameters such as grain size distribution and Atterberg's limits of the flood mud are also determined. The outcomes of these results will lead to the promotion of application of flood mud to sustainable pavement.

\section{Materials and testing procedures}

The flood mud sample was air dried at a laboratory after removal of the debris from the soil sample. The soil sample was sieved through a $425 \mu \mathrm{m}$ sieve to confirm the uniformity of materials [15], and the passing material was used throughout the experiments. The biomass silica stabilizing agent, also known as SH85 in the commercial sphere, was supplied in powder form by Probase Manufacturing Sdn Bhd, a local company in Johor state of Malaysia.

Basic soil property tests including specific gravity, grain size, Atterberg limit, and standard proctor compaction were conducted using the recommendations of the British Standard Institution [35]. The coefficient of permeability of flood mud sample was measured by a constant head permeability test. Compressibility of compacted flood mud sample was determined through the 1D consolidation test. The UCS tests were carried out to determine the soil strength of untreated and treated flood mud samples. The flood mud samples were investigated using the UCS test, and their Optimum Moisture Content (OMC) and Maximum Dry Density (MDD) were determined using the compaction test. A set of cylindrical soil specimens characterized by a diameter of $38 \mathrm{~mm}$ and a height of $76 \mathrm{~mm}$ was prepared for the UCS test. These samples were tested at a constant strain rate of $1.52 \mathrm{~mm} / \mathrm{min}$. For the treated cases, $2 \%, 4 \%$, and 9\% SH85 contents were mixed with flood mud samples and cured for three and seven days at room temperature. With these low SH85 contents, the treated samples were prepared based on equal OMC and MDD values of the untreated sample [7]. According to the MDD value, the mixture was then transferred to a stainless steel UCS mold. The sample was compressed using a pair of pistons at both ends of the mold. A steel plunger was used to extrude the cylindrical samples and then, kept in a polythene bottle. In order to maintain humidity and temperature of the sample, the bottle was placed above a water level in a closed container during the curing period. All the tests were conducted according to the British Standard Institution [35].

The microstructure of flood mud samples was 
observed by FESEM and Energy Dispersive X-ray Spectrometer (EDX). The EDX test was conducted to determine the elemental composition of individual points or to map out the lateral distribution of elements from the imaged area. The FESEM test provides topographical and elemental information with a virtually unlimited depth of the field.

\section{Result and analysis}

The basic properties of the soil are shown in Table 1. The liquid and plastic limits were $42 \%$ and $26 \%$, respectively, and the plasticity index was $16 \%$. Based on the wet sieving and hydrometer analysis test, the flood mud sample consisted of $0 \%$ gravel, $89.31 \%$ sand, $10.43 \%$ silt, and $0.26 \%$ clay. The soil sample was categorized as Clayey Sand (SC) based on the Unified Soil Classification System (USCS). MDD and OMC values were $1.626 \mathrm{Mg} / \mathrm{m}^{3}$ and $18 \%$, respectively (see Figure 1). The MDD (1.513-1.680 $\left.\mathrm{Mg} / \mathrm{m}^{3}\right)$ and OMC (11-19\%) values were within the typical range of the CS materials

Table 1. Basic properties of flood mud sample.

\begin{tabular}{lll}
\hline No. & \multicolumn{1}{c}{ Properties } & \multicolumn{1}{c}{ Value } \\
\hline 1. & $\begin{array}{l}\text { Proctor density } \\
\text { Optimum moisture content } \\
\text { Maximum dry density }\end{array}$ & $\begin{array}{l}18 \% \\
1.626 \mathrm{Mg} / \mathrm{m}^{3}\end{array}$ \\
& \\
2. & Specific gravity & 2.74 \\
& & \\
3. & Atterberg limits & \\
& Liquid limit & $42.07 \%$ \\
& Plastic limit & $26.15 \%$ \\
& Plasticity Index & $15.92 \%$ \\
& Group of soil & SC (clayey sands)
\end{tabular}

4. Permeability

Coefficient of permeability $1.145 \times 10^{-5} \mathrm{~cm} / \mathrm{sec}$

5. Grain size distribution

$\begin{array}{ll}\% \text { of gravel } & 0 \% \\ \% \text { of sand } & 89.31 \% \\ \% \text { of silt and clay } & 10.43 \% \text { and } 0.26 \%\end{array}$

6. Unconfined compressive strength (untreated)

7. Consolidation (untreated)

Compressive index, $C_{c} \quad 0.063$

Recompressive index, $C_{r} \quad 0.041$

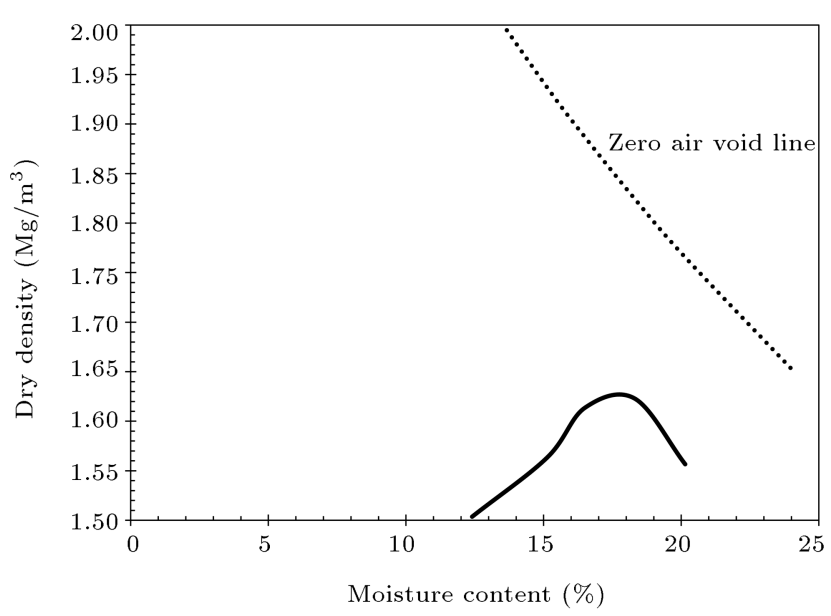

Figure 1. The compaction test result on of flood mud.

proposed by AASHTO T99 [36]. A zero-air void curve was located above the compaction curve so that it can be confirmed that the upper limit of dry density of any moisture content was based on theory [37].

Figure 2 displays the stress-strain curve of the treated flood mud samples at $0 \%, 2 \%, 4 \%$, and $9 \%$ SH85 contents for three and seven days of curing. The larger SH85 content exhibited higher strength. The peak strength occurred at large strains between $7 \%$ and $8 \%$. Soil samples with $4 \%$ and $9 \%$ SH85 contents tend to increase gradually, compared to the $2 \%$ SH85 treated sample. The treated samples exhibited brittle behavior at their peak strength, followed by a sudden decrease. The strength of the treated soil increased by two to seven times more than that of the untreated soil, where the highest soil strength was recorded at $949 \mathrm{kPa}$ when treated with $9 \%$ SH85 for seven days. The achieved strength of treated soil was relatively higher than that of the treated laterite soil in the previous study conducted by Latifi et al. [33]. They obtained

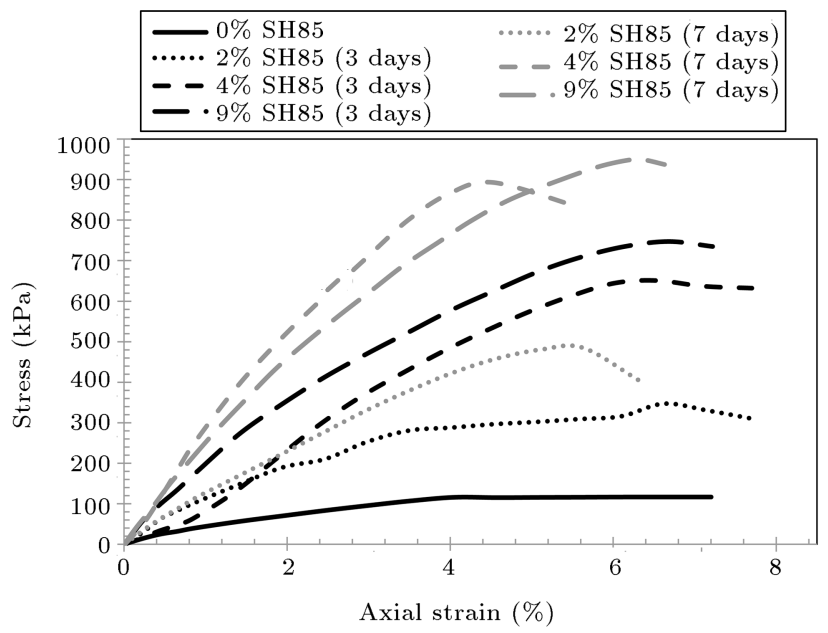

Figure 2. Stress versus strain curve of SH85 treated samples after 3 and 7 days of curing. 


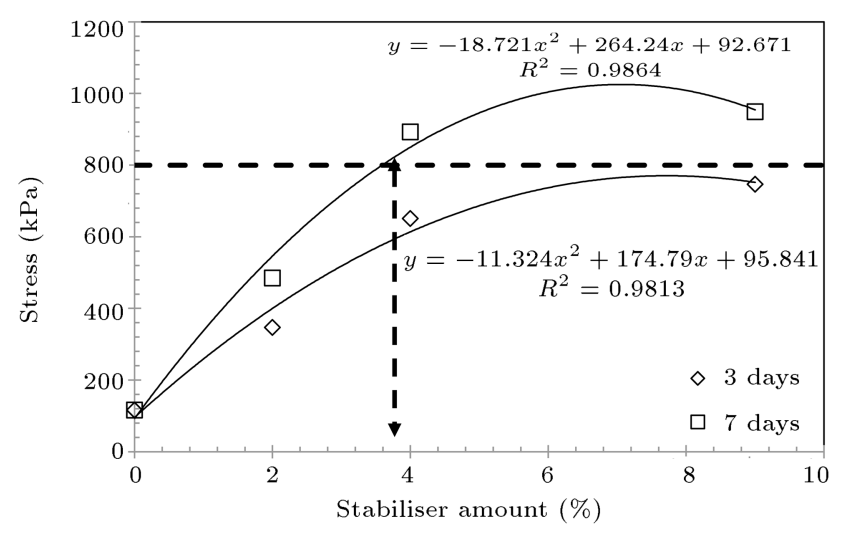

Figure 3. Unconfined Compressive Strength (UCS) of SH85 treated samples for different stabilizer stabilizing contents and curing periods.

soil strength five times higher than the previous records after treating the laterite soil with $9 \%$ SH85 content for a seven-day curing period.

Figure 3 illustrates the relationship between SH85 content and UCS in different curing periods. A polynomial trend was observed with an $R^{2}$ value greater than $95 \%$. It is evident that during the treatment process, the shear strength increased significantly with the addition of $2 \%$ SH85 content for both three and seven days of curing. The three-day UCS value was $651 \mathrm{kPa}$ for the $4 \%$ SH85 treated sample and it slightly increased to $747 \mathrm{kPa}$ for $9 \%$ of the SH85 treated sample. However, upon seven days of curing, the UCS increased drastically from $4 \%$ to $9 \%$ of SH85. The UCS increased up to $949 \mathrm{kPa}$ from $893 \mathrm{kPa}$. It is of interest that seven-day UCS of the $4 \%$ SH85 treated sample meets the requirements set by PWD, Malaysia. Generally, the UCS tremendously increased upon an increase in SH85 content and curing time. Based on the relationship (Figure 3), the SH85 can be reduced from $4 \%$ to $3.6 \%$ to obtain a seven-day UCS value of $800 \mathrm{kPa}$ (a straight line arrow).

Figure 4 shows the void ratio, e versus log stress, and $\mathrm{p}$ curve obtained from the oedometer test for both

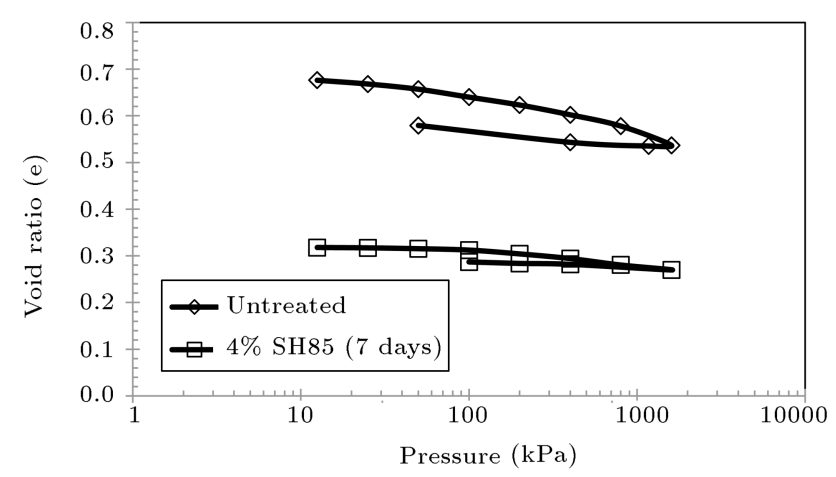

Figure 4. Graph of e-log p curve for untreated and treated soils with $4 \%$ of SH $85+7$ days cured sample obtained from Oedometer test. untreated and treated soils of $4 \%$ SH85 treated sample cured for seven days. This sample was chosen because its UCS exceeded the requirement $(0.8 \mathrm{MPa})$ of PWD. The values of compression index, $C_{c}$, and recompression index, $C_{r}$, are 0.063 and 0.041 , respectively, while $C_{c}$ and $C_{r}$ values of the treated samples are 0.018 and 0.0083 , respectively. In other words, compared to the untreated sample, $C_{c}$ value of the treated sample was reduced by 0.045 , indicating a significant improvement of the resistance to compressibility due to SH85 treatment. A similar finding was obtained by Latifi et al. [33], who concluded that the SH85 treatment of laterite soil reduced the compressibility properties of the treated soil. They believed that this reduction resulted from the formation of new cementing products, which led to higher resistance to compression stress.

Figure 5 shows the morphology of the untreated sample and $4 \%$ SH85 treated sample on seven days of curing. The soil structure was enlarged 18000 times. The circle on the FESEM micrograph in Figure 5(a) presents the pore spaces and voids on the untreated flood mud sample. This confirmed that the soil structure was looser with weaker interparticle forces before being treated with SH85. The circle in Figure 5(b) shows the formation of new cementation products (white colored lump) in the treated soil samples. In addition, the porosity is reduced significantly after the SH85 treatment (comparing Figure 5(a) and (b)) due to the filling of cementitious products into the pores of the soil structure.

Figure 6 shows EDAX patterns of the untreated and treated samples. Silica and aluminum are dominant elements in the untreated sample (Figure 6(a)). The concentration of silica was $25.8 \%$, which was higher than that of aluminum present in the soil structure at $12.1 \%$. The high amount of amorphous silica ( $\mathrm{Si}$ ) and aluminum (Al) represents the main source for pozzolanic reactions to produce high-strength material when treated with a stabilizing agent [38]. An additional mineral composition of calcium was clearly detected in the soil structure of $4 \%$ SH85 treated sample (Figure 6(b)). The concentration of silica and aluminum decreased to $11.6 \%$ and $9.2 \%$, respectively, after the treatment. The aluminum to silica ratio reduced from 2.13 to 1.26 and the calcium element was found after treatment with SH85 at the calcium-andsilica ratio of 0.58 . Table 2 shows the corresponding changes in the ratios of $\mathrm{Al}: \mathrm{Si}$ and $\mathrm{Ca}: \mathrm{Si}$ for the

Table 2. Al:Si and Ca:Si ratios for untreated and treated soil by $4 \%$ SH85 obtained from EDAX analysis test result.

\begin{tabular}{ccc}
\hline Al:Si and & Untreated & Curing periods \\
\cline { 3 - 3 } $\mathrm{Ca}: \mathrm{Si}$ & soil & $\mathbf{7}$ days \\
\hline $\mathrm{Al} / \mathrm{Si}$ & 0.47 & 0.79 \\
$\mathrm{Ca} / \mathrm{Si}$ & 0 & 0.46 \\
\hline
\end{tabular}




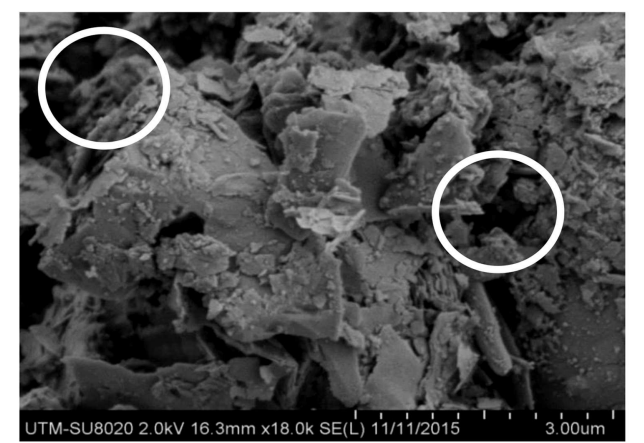

(a) Untreated

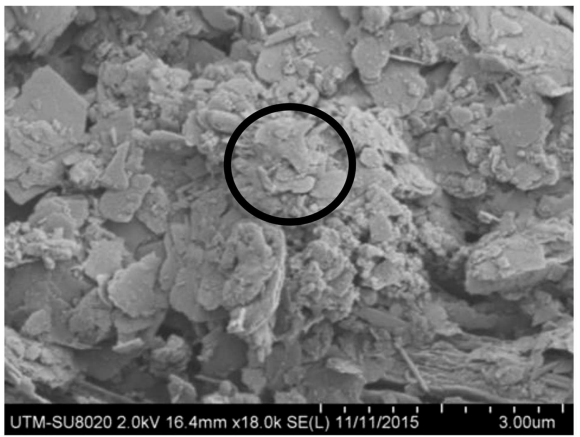

(b) Treated

Figure 5. Field-Emission Scanning Electron Microscopy (FESEM) results for of the (a) Untreated soil sample and (b) $4 \%$ of SH85 treated soil sample after 7 days of curing period.

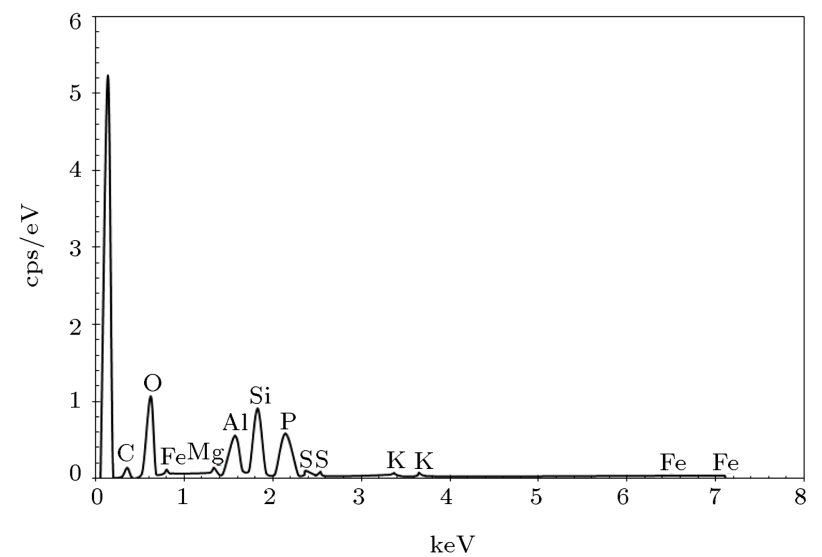

(a) Untreated

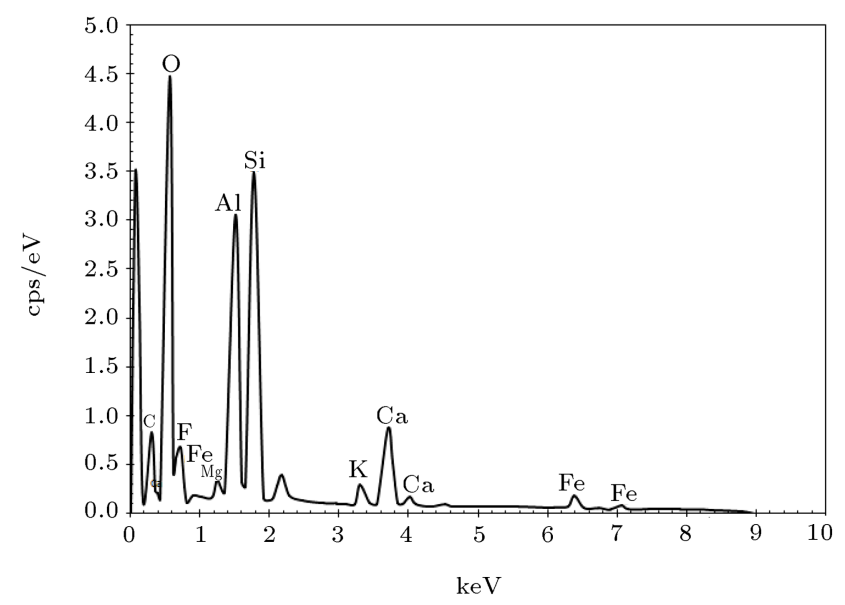

(b) Treated with $4 \%$ of SH85 treated soil sample after 7 days curing period

Figure 6. EDAX patterns for of the untreated and treated soil samples.

untreated and treated soils. A slight change in Al:Si ratio and $\mathrm{Ca}: \mathrm{Si}$ ratio for the $\mathrm{SH} 85$ stabilized samples between the untreated and treated soils proved that a chemical reaction occurred when the soil sample was treated with SH85 after seven days of treatment.
A cation exchange and chemical bonding contributed to the strength development. When the SH85 was added to a clay-water system, the divalent calcium cations would be absorbed into the diffuse double layer. A calcium aluminate hydrate product was therefore developed with the presence of calcium ions and water [20]. The EDAX pattern analysis result was consistent with the FESEM analysis result, showing the viability of the new cementation product due to the SH85 treatment. The presence of calcium concentration in SH85 provides free $\mathrm{Ca}^{+}$ions for the chemical reaction with silica and alumina present in the flood mud. This chemical reaction produces new cementation compounds: calcium silicate hydrates (C$\mathrm{S}-\mathrm{H}$ ) and calcium aluminate hydrates (C-A-H). The same finding was observed by Latifi et al. $[31,33]$ on the treated laterite and clay soils, where new compounds were developed and roughly recognized as Calcium Aluminate Hydrate $(\mathrm{CAH})$.

\section{Conclusions}

In conclusion, the flood mud sample obtained from the flooded area at Kuala Krai, Kelantan was categorized as Clayey Sand (SC) and could be improved by SH85. The $4 \%$ SH85 was the minimum content for improving flood mud to be stabilized as a subgrade material of a low traffic volume road (UCS > $800 \mathrm{kPa}$ ), as specified by the Public Work Department of Malaysia (PWD). The resistance to compressibility of the mud flood soil was significantly enhanced after treatment with $4 \%$ SH85. Field-Emission Scanning Electron Microscopy (FESEM) results indicated that cementitious products filled up the pores in the soil structure, hence causing a reduction in porosity. These cementitious products increased the cementation bonds and interparticle forces, resulting in the Unconfined Compressive Strength (UCS) and compressibility improvement. Energy-Dispersive X-Ray Spectrometry (EDX) micrographs demonstrated the formation of $\mathrm{C}$ - 
$\mathrm{A}-\mathrm{H}$ and $\mathrm{C}-\mathrm{S}-\mathrm{H}$ as cementitious products in the soil structure. The outcome of this research led to the utilization of the treated flood mud as the stabilized subgrade material in low traffic volume roads, which is beneficial in terms of engineering, environment, and economical perspectives.

\section{Acknowledgement}

The corresponding author would like to thank to Universiti Teknologi Malaysia for the financial support under University Research Grant (14H33) and the second last author is grateful to the financial support from the Thailand Research Fund under the TRF Senior Research Scholar program Grant No. RTA5980005 and Suranaree University of Technology.

\section{References}

1. Agence France-Presse Asia One "Floods kill 21 in Malaysia, waters recede", 31 December (2014).

2. Rashid, A.S.A., Latifi, N., Meehan, C.L., and Manahiloh, K.N. "Sustainable improvement of tropical residual soil using an environmentally friendly additive", Geotechnical and Geological Engineering, 35(6), pp. 2613-2623 (2017).

3. Shakir, A.A. and Mohammed, A.A. "Manufacturing of bricks in the past, in the present and in the future: A state of the art Review", International Journal of Advances in Applied Sciences, 2(3), pp. 145-156 (2013).

4. Jabatan Kerja Raya "Design guide for alternative pavement structure (low volume roads)", Jabatan Kerja Raya Malaysia (JKR), Kuala Lumpur, Malaysia (2012).

5. Datta, T., Roy, T.K., and Roy, S.K. "Effect of subgrade on rutting of flexible pavement in low volume roads", Proceedings of Indian Geotechnical Conference, Rorkee, India, pp. 22-24 (2013).

6. AwgShahminan, D.N.I.A., Rashid, A.S.A., Ridzuan Bunawan, A., Yaacob, H., and Noor, N.M. "Relationship between strength and liquidity index of cement stabilized laterite for subgrade application", International Journal of Soil Science, 9(1), pp. 16-21 (2014).

7. Rashid, A.S.A., Kalatehjari, R., Noor, N.M., Yaacob, H., Moayedi, H., and Sing, L.K. "Relationship between liquidity index and stabilized strength of local subgrade materials in a tropical area", Measurement: Journal of the International Measurement Confederation, 55, pp. 231-237 (2014).

8. Aflaki, E., Sedighi, P., and Eslami, A. "Study on the failure behavior of three different stabilized problematic soils", Scientia Iranica, A, 21(4), pp. 1231-1240 (2014).

9. Arulrajah, A., Mohammadinia, A., D' Amico, A., and Horpibulsuk, S. "Effect of lime kiln dust as an alternative binder in the stabilization of construction and demolition materials", Construction and Building Materials, 152, pp. 999-1007 (2017).

10. Ebadi, M., Habibagahi, G., and Hataf, N. "Effect of cement treatment on soil non-woven geotextile interface", Scientia Iranica, A, 22(1), pp. 69-80 (2015).

11. Hassan, W.H.W., Rashid, A.S.A., Latifi, N., Horpibulsuk, S., and Borhamdin, S. "Strength and morphological characteristics of organic soil stabilized with magnesium chloride", Quarterly Journal of Engineering Geology and Hydrogeology, 50(4), pp. 454-459 (2017).

12. Hesham, A.H.I. "Cement kiln dust chemical stabilization of expansive soil exposed at El-Kawther quarter, Sohag Region, Egypt", International Journal of Geosciences, 4, pp. 1416-1424 (2013).

13. Jin, L.J., Yunus, N.Z.M., Hezmi, M.A., Rashid, A.S.A., Marto, A., Kalatehjari, R., Pakir, F., Mashros, N., and Ganiyu, A. "Predicting the effective depth of soil stabilization for marine clay treated by biomass silica", KSCE Journal of Civil Engineering, 22(11), pp. 4316-4326 (2018).

14. Latifi, N., Rashid, A.S.A., Siddiqua, S., and Horpibulsuk, S. "Micro-structural analysis of strength development in low- and high swelling clays stabilized with magnesium chloride solution - A green soil stabilizer", Applied Clay Science, 118, pp. 195-206 (2015).

15. Latifi, N., Marto, A., Rashid, A.S.A., and Yii, J.L.J. "Strength and physico-chemical characteristics of fly ash-bottom ash mixture", Arabian Journal for Science and Engineering, 40(9), pp. 2447-2455 (2015).

16. Latifi, N., Rashid, A.S.A., Siddiqua, S., and Majid, M.Z.A. "Strength measurement and textural characteristics of tropical residual soil stabilised with liquid polymer", Measurement: Journal of the International Measurement Confederation, 91, pp. 46-54 (2016).

17. Latifi, N., Horpibulsuk, S., Meehan, C.L., Majid, M.Z.A., and Rashid, A.S.A. "Xanthan gum biopolymer: An eco-friendly additive for stabilization of tropical organic peat", Environmental Earth Sciences, 75(9), 825: 1-10 (2016).

18. Latifi, N., Rashid, A.S.A., Marto, A., and Tahir, M.M. "Effect of magnesium chloride solution on the physicochemical characteristics of tropical peat", Environmental Earth Sciences, 75(3), pp. 1-9 (2016).

19. Latifi, N., Rashid, A.S.A., Ecemis, N., Tahir, M.M., and Marto, A. "Time-dependent physicochemical characteristics of Malaysian residual soil stabilized with magnesium chloride solution", Arabian Journal of Geosciences, 9(1), pp. 1-12 (2016).

20. Latifi, N., Eisazadeh, A., Marto, A., and Meehan, C.L. "Tropical residual soil stabilization: A powder form material for increasing soil strength", Construction and Building Materials, 147, pp. 827-836 (2017). 
21. Latifi, N., Vahedifard, F., Ghazanfari, E., and Rashid, A.S.A. "Sustainable usage of calcium carbide residue for stabilization of clays", Journal of Materials in Civil Engineering, 30(6), p. 04018099 (2018).

22. Phummiphan, I., Horpibulsuk, S., Phoo-ngernkham, T., Arulrajah, A., and Shen, S.L. "Marginal lateritic soil stabilized with calcium carbide residue and fly ash geopolymers as a sustainable pavement base material", Journal of Materials in Civil Engineering, 29(2), 04016195 (2017).

23. Phummiphan, I., Horpibulsuk, S., Sukmak, P., Chinkulkijniwat, A., Arulrajah, A., and Shen, S.L. "Stabilisation of marginal lateritic soil using high calcium fly ash based geopolymer", Road Materials and Pavement Design, 17(4), pp. 877-891 (2016).

24. Rashid, A.S.A., Zainudin, Z., Md Noor, N., and Yaacob, H. "Effect of stabilized laterite on California bearing ratio (CBR) and unconfined compressive strength (UCS)", Electronic Journal of Geotechnical Engineering, 18(X), pp. 5655-5660 (2013).

25. Rashid, A.S.A., Shahrin, M.I., Horpibulsuk, S., Hezmi, M.A., Yunus, Z.M., and Borhamdin, S. "Development of sustainable masonry units from mud flood soil: strength and morphology investigations", Construction and Building Materials, 131, pp. 682-689 (2017).

26. Sukmak, P., Horpibulsuk, S., Shen, S.L., Chindaprasirt, P., and Suksiripattanpong, C. "Factors influencing strength development in clay-fly ash geopolymer", Construction and Building Materials, 47, pp. 1125-1136 (2013).

27. Sukmak, P., Silva, P.D., Horpibulsuk, S., and Chindaprasirt, P. "Sulfate resistance of clay-Portland cement and clay-high calcium fly ash geopolymer", Journal of Materials in Civil Engineering, ASCE, 27(5), 04014158 (2015).

28. Yoobanpot, N., Jamsawang, P., and Horpibulsuk, S. "Strength behavior and microstructural characteristics of soft clay stabilized with cement kiln dust and fly ash residue", Applied Clay Science, 141, pp. 141-151 (2017).

29. Zainuddin, N., Mohd Yunus, N.Z., Mohammed AlBared, M.A., Marto, A., Harahap, I.S.H., and Rashid, A.S.A. "Measuring the engineering properties of marine clay treated with disposed granite waste", Measurement: Journal of the International Measurement Confederation, 131, pp. 50-60 (2018).

30. Kua, T.A., Arulrajah, A., Horpibulsuk, S., Du, Y.J., and Suksiripattanapong, C. "Engineering and environmental evaluation of spent coffee ground stabilised with industrial by-products as a road subgrade material", Clean Technologies and Environmental Policy, 19(1), pp. 63-75 (2017).
31. Latifi, N., Christopher, L., Meehan, C.L., Majid, M.Z.A., and Horpibulsuk, S. "Strengthening using a calcium-based non-traditional additive: A micro-level study", Applied Clay Science, 132-133, pp. 182-193 (2016).

32. Latifi, N., Eisazadeh, A., and Marto, A. "Strength behavior and microstructural characteristic of tropical laterite soil treated with the sodium silicate-based liquid stabilizer", Environmental Earth Science, 72, pp. 91-98 (2014).

33. Latifi, N., Marto, A., and Eisazadeh, A. "Physicochemical behavior of tropical laterite soil stabilized with non-traditional additive", Acta Geotechnica, 11, pp. 433-443 (2015).

34. Turkoz, M., Savas, H., Acaz, A., and Tosun, H. "The effect of magnesium chloride solution on the engineering properties of clay soil with expansive and dispersive characteristics", Applied Clay Science, 101, pp. 1-9 (2014).

35. British Standard Institution, "Method of test for soils for civil engineering purposes", BS 1377, London (1990).

36. AASTHO T99. "Standard method of test for moisturedensity relations of soils using a $2.5-\mathrm{kg}(5.5-\mathrm{lb})$ rammer and a 305-mm (12-in.) drop", American Association of State Highway and Transportation Officials (AASHTO) (2017).

37. Liu, C. and Evett, J., Soils and Foundations, 8th Edn., Pearson Prentice Hall, New Jersey (2014).

38. Mathew, B.J., Sudhakar, M., and Natarajan, C. "Development of coal ash - GGBS based geopolymer bricks", European International Journal of Science and Technology, 2(5), pp. 133-139 (2013).

\section{Biographies}

Nurul Ain Ibrahim is a Master's student at Department of Geotechnics and Transportation, School of Civil Engineering, Faculty of Engineering, Universiti Teknologi Malaysia (UTM), Johor, Malaysia. Her research focuses on soil stabilization method for improving engineering properties of problematic soil. She had a Bachelor's degree in Civil Engineering from Universiti Teknologi Malaysia (UTM).

Ahmad Safuan A. Rashid joined UTM as an academic staff in December 2005 after completing his Master's degree in the same institution. He obtained his $\mathrm{PhD}$ degree from the University of Sheffield in the UK in September 2011. His expertise is focused on small-scale physical modelling and he has conducted a study on behaviour of failure on Deep Mixing (DM) Method as a foundation. He teaches soil mechanics, geotechnics, and laboratory subjects for undergraduates. He has also supervised more than 40 students cutting across undergraduate, master, and $\mathrm{PhD}$ levels. 
Nor Zurairahetty Mohd Yunus is a senior lecturer at the School of Civil Engineering, Faculty of Civil Engineering, UTM. She joined UTM in August 2006 after completing her undergraduate study at UTM. After completing her master study in 2008, she pursued her study at University of Nottingham in United Kingdom and completed it in 2012. Now, she is a director of Geotechnics and Transportation Department in School of Civil Engineering, UTM.

Nima Latifi is a post-doctoral researcher at the Mississippi State University, United State. He holds B.Eng. (Civil) (Hon.) from Babol Noushirvani University of Technology, M.Sc. from University of Mazandaran, and PhD (Geotechnics) from Universiti Teknologi Malaysia. His current major researches are focused on soil stabilization and soil mechanics.

Suksun Horpibulsuk obtained a B.Eng. (Civil Engineering) with Honors Award from Khon Kaen University, Thailand in 1996. Professor Suksun was subsequently granted a scholarship by the Royal Thailand Government to pursue an M.Eng. degree in Soil Engineering at Asian Institute of Technology and duly completed it in 1998. He then received a prestigious Monbusho scholarship from the Japanese Government to pursue his $\mathrm{PhD}$ in Geotechnical Engineering at Saga University in Japan which he duly completed in 2001. Professor Suksun joined Suranaree University of Technology (SUT) as a lecturer in 2002. His outstanding research, teaching, and service for the university, community, and profession over the years were duly recognized when he was promoted to the level of the Full Professor in 2010. He is a Professor of School of Civil Engineering and a Founder Director of Center of Excellence in Innovation for Sustainable Infrastructure Development at SUT. He is also an Academic Senate member of SUT and Rajamangala University of Technology Isan and a board member of the Research and Development of Knowledge Management of Metropolitan Waterworks Authority of Thailand. He is presently the President of the International Geosynthetics Society (IGS) - Thailand Chapter, and an Adjunct Professor at Swinburne University of Technology, Australia. He also serves as an editor and reviewer of several prestigious national and international journals. His most significant contributions have been made in the field of ground improvement techniques, specifically issues associated with compaction, earth reinforcement, and chemical stabilization. He has been awarded a large number of competitive research grants totaling US $\$ 5$ million. He has published extensively with over 400 technical publications, including over 200 in leading journals. He has a H-index of 32 (Scopus) and currently averages 900 (Scopus) citations per annum. He is a senior professional engineer accredited by Council of Engineers, Thailand. Due to his outstanding contributions for the profession and community as well as his national and international recognition, he was nominated as a TRF Senior Scholar in 2013 and 2016 by the Thailand Research Fund. 